\title{
EGU21-9956
}

https://doi.org/10.5194/egusphere-egu21-9956

EGU General Assembly 2021

(c) Author(s) 2022. This work is distributed under

the Creative Commons Attribution 4.0 License.

\section{A modern prototype three-layer stratification in the Arctic Ocean since the Miocene}

\author{
Akil Hossain ${ }^{1}$, Gregor Knorr ${ }^{1}$, Wilfried Jokat ${ }^{1,2}$, and Gerrit Lohmann ${ }^{1}$ \\ ${ }^{1}$ Alfred Wegener Institute for Polar and Marine Research, Paleoclimate Dynamics, Bremerhaven, Germany \\ (akil.hossain@awi.de) \\ ${ }^{2}$ University of Bremen, Department of Geoscience, 28359 Bremen, Germany
}

The tectonic opening of the Fram Strait (FS) was critical to the water exchange between the Atlantic Ocean and the Arctic Ocean, and caused the transition from a restricted to a ventilated Arctic Ocean during early Miocene. If and how the water exchange between the Arctic Ocean and the North Atlantic influenced the global current system is still disputed. We apply a fully coupled atmosphere-ocean-sea-ice model to investigate stratification and ocean circulation in the Arctic Ocean in response to the opening of the FS during early to middle Miocene. Progressive widening of the FS gateway in our simulation causes a moderate warming, while salinity conditions in the Nordic Seas remain similar. On the contrary, with increasing FS width Arctic temperatures remain unchanged and salinity changes appear to steadily become stronger. For a sill depth of $\sim 1500 \mathrm{~m}$, we achieve ventilation of the Arctic Ocean due to enhanced import of saline Atlantic water through a FS width of $\sim 105 \mathrm{~km}$. Moreover, at this width and depth, we detect a modern-like three-layer stratification in the Arctic Ocean. The exchange flow through FS is characterized by vertical separation of a low salinity cold outflow from the Arctic Ocean confined to a thin upper layer, an intermediate saline inflow from the Atlantic Ocean below and a cold bottom Arctic outflow. Using a significantly shallower and narrower FS during the early Miocene, our study suggests that the ventilation mechanisms and stratification in the Arctic Ocean are comparable to the present-day characteristics. 